\title{
Domestic Commitment, Financial Capability and Network Affiliation Affecting on Business Performance of Women Entrepreneurs in Gampaha District, Sri Lanka
}

\author{
Dr. H. K. G. S. Ranasinghe \\ ${ }^{*}$ Department of Entrepreneurship, Faculty of Management Studies and Commerce, University of Sri Jayewardenepura, Sri Lanka \\ DOI: 10.29322/IJSRP.11.07.2021.p11539 \\ http://dx.doi.org/10.29322/IJSRP.11.07.2021.p11539
}

\begin{abstract}
-
Purpose- This empirical research proposes to find out the impact of individual factors on the business performance of women entrepreneurs with special reference to Gampaha district, Sri Lanka.

Design/ Methodology/ Approach- A theoretical framework developed by the author is proposed based on how three main independent variables of domestic commitment, financial capabilities and network affiliation influence the business performance of women entrepreneurs. The structured questionnaires, developed by the author were distributed among 185 of women entrepreneurs in Small Enterprises Development Centre in the Gampaha district. The collected data were analyzed using Pearson correlation analysis and multiple linear regression analysis.

Findings-Results revealed that the independent variables of financial capabilities, domestic commitment and network affiliation have a positive significant impact on the dependent variable which is business performance. The results further showed that financial capability has the highest impact on business performance of women entrepreneurs in Gampaha district, Sri Lanka.

Research Implications- The study has several limiting factors. The scope of the study had to be restricted to women entrepreneurs in Gampaha district, who were selected through simple random sampling method.

Practical Implications- The findings recommend to promote entrepreneurial culture in Sri Lanka, improve the accessibility to finance, improve mentorship, advisory and business supportive services in order to enhance the business performance.

Originality/ Value- The study suggests that the theories adopted from western developed countries in relation to women entrepreneurship should be cautiously tested and examined before adopting to developing Asian country like Sri Lanka.
\end{abstract}

Index Terms- Women Entrepreneurship, Business Performance, Domestic Commitment, Financial Capabilities, Network Affiliation

\section{INTRODUCTION}

Entrepreneurship serve an important task in elevating the developing economies and this process has gained momentum (Seelanathan, 2013). Further, people have become aware of the necessity to adopt entrepreneurship (United Nations University, 2013). Women entrepreneurs seem to be taking part in this process in an active manner (UNDP, 2012). Considering the increasing trend in the entrepreneurship and the motivation of women to start their own businesses in the modern era, tend to change the notion that men are "bread winners" and women are "house makers" (Government of Sri Lanka, Sri Lanka, 2019).

\section{Differentiate Men and Women Businesspersons}

According to Malaya 2006, in an attempt to differentiate businesspersons as men and women stating their priorities in diminishing order is presented in the table 1 as follows.

\section{Table 1: Male and Women Entrepreneurs}

\begin{tabular}{ll}
\hline \multicolumn{1}{c}{ Men Entrepreneurs } & \multicolumn{1}{c}{ Women Entrepreneurs } \\
\hline Making Profits & Making Profits \\
Providing good product and service to clients & Providing good product and service to clients \\
Try to balance their work \& family tasks & Providing jobs to people \\
Having a steady basis of livelihood & Try to balance their work \& family tasks \\
Increasing quality and lifestyle of workers & Increasing quality and lifestyle of workers \\
Doing operation continually for their business & Doing operation continually for their business \\
Increasing business & Having a steady basis of livelihood \\
Providing jobs to people & operate their talents and skills \\
Increasing financial freedom & Get advantages of opportunities \\
Provide acceptable family support & Increasing financial freedom \\
\hline
\end{tabular}

Source : Malaya,(2006) 
Normally, the ventures of women entrepreneurs tend to have a lesser number of sales, revenue and assets in comparison with their male counterparts. United States has on the average, entrepreneurial ventures of men as twice as large as women entrepreneurial ventures in relation to both sales and assets (Nanayakkara, 2011), Country like Sri Lanka can be benefitted by entrepreneurship run by women which is vital. Lately, role of women entrepreneurs has been recognized as very important and highlighted the role it could play in SMEs sector and enhancing nations' well-being (Fatima, Hasan and Almubarak, 2016).

World's population has about 50 percent of women (Adu, 2016) During the past two decades their outstanding representation in the labor force was shown, and there exists drastic variances in the results they achieve or wages they earn, despite being equivalent in number as well as participation in economic activities (Adu, 2016). Many countries in Asia witnessed the same trend of population figures elevating the role of women in the labor market which led to higher purchasing power and captured an important part of continued economic growth (Food and Agriculture Organization of the United Nations, 2013). Sri Lanka has 52 present of women and their national contribution to the Gross Domestic Products is around 35 presence (Government of Sri Lanka, Sri Lanka (2019). Further, in 2018 Sri Lanka had approximately 0.6 percent females of the total employed population, representing the employer category (Department of Census and Statistics, 2018). It is also clear that women owned businesses are regarded as fastest growing entrepreneurial populations in the world (Brush, 2012).The lower levels of contribution of women to the local economy relates to shortage of Sri Lankan women involved in entrepreneurship and the scarcity of successful women in this category (Ranasinghe, 2008).

\section{Current Situation of Women Entrepreneurship}

Entrepreneurs are considered as the change agents around the world (Mokhtar, 2017). Entrepreneurs search for creative ideas and take action to implement them through innovativeness on an enormous scale. Entrepreneurship serves as the major input in every country. It is vital to have a large number of entrepreneurs in a developing a country like Sri Lanka. Hence, studying the reasons for poor performance among women entrepreneurs (Mwania, 2015) is very much appropriate. Women entrepreneurs are regarded as one of the valuable resources to a developing country like Sri Lanka in this current situation. In the present context, all over the world, women entrepreneurship has increased to a greater extent, and the fact that entrepreneurship is vital for economic growth is widely recognized (Mokhtar, 2017). The economic growth and development of the nation have been contributed by women entrepreneurs, in job creation as well as revenue generation (Mokhtar, 2017). A change in the socioeconomic status is brought about through participation of women in entrepreneurship which helps the development, and improves the standard of living which in turn reduces the poverty in a country (Dharmaratne, 2012). The Sri Lankan context appear to be similar to the international situation as many of the female entrepreneurs are performing well in comparison to most of their male counterparts. Most of the successful women entrepreneurs have crossed the local boundaries and penetrated the international market. Since business performance of female entrepreneurs are at best in comparison to male entrepreneurs, during the last few decades, it became a major necessity of research, world over, to examine the success factors of their performance. Hence identifying those factors highlighted as a main research problem to solve. Based on these facts, the researcher will attempt to fill the gap in this research scope in Sri Lankan context. The research problem is framed as, "Whether, there is an impact of individual factors such as, Domestic Commitment, Financial Capabilities and Network Affiliation towards the business performance of women entrepreneurs in Gampaha district, Sri Lanka?"

\section{Entrepreneur's Role and the Sri Lankan Economy}

History provides evidence that entrepreneur's activity in the Sri Lankan economy, does not have a considerable contribution from the women entrepreneurship to its development. However, in the recent past, there is a substantial contribution from women entrepreneurs to the Sri Lankan economy, which changed the situation, even though their numbers are still relatively low (Hemalatha,2005). The above evidence indicates that understanding the selected factors are very essential. Researchers in this field have conducted only few studies on the Sri Lankan context when compared with the western countries. Moreover, it is clear that there is a knowledge gap existing in this area of research (Gamage, 2003). Therefore, the primary objective of this research is to examine the impact of these factors on business performance of women entrepreneurs with special reference to Gampaha district, Sri Lanka.

\section{IDENTIFY, RESEARCH AND COLLECT IDEA}

Multidisciplinary perspectives and multidisciplinary theories have been involved for entrepreneurship studies (Pooja jha and, MunishMakkad, 2019). Five theoretical perspectives describe performance which are: individual motivations and goals; social learning (entrepreneurial socialization); network affiliation (contacts and membership in organizations); human capital (level of education, business skills); and environmental influences (location, sectoral participation, and sociopolitical variables) (Hisrich,1997). Women entrepreneurs take part in the economic activity and their participation is considered to be valuable. This study considered the views expressed by women business owners in relation to the factors forming barriers toward or hinders their performance in business (Adu, 2016).

\section{Entrepreneurship}

This publication is licensed under Creative Commons Attribution CC BY.

http://dx.doi.org/10.29322/IJSRP.11.07.2021.p11539

WWW.ijsrp.org 
Market opportunities widen as a society transfers gradually from under development to the phase of development, while individuals have access to more finance, increased purchasing power, more skills, abilities and motives. This allows the social and economic environments to become more favorable towards progress and more openings for entrepreneurship (Mwania, 2015). Hence, "entrepreneurship" is known as the process through which individuals chase opportunities in spite of the resources, they now control. The crux of entrepreneurial behavior can be stated as identifying opportunities and take action to pursue beneficial ideas into practice (Adu, 2016).

\section{Women Entrepreneurship}

Although women play an active role in micro and small-scale enterprises (MSEs) they face specific issues and challenges in evolving their businesses. Women very often face gender bias in the socio-economic environment in which they operate as commonly acknowledged, in addition to the problems faced by all small-scale entrepreneurs. The 2015 Global Entrepreneurship Monitor (GEM) Special Report on Women Entrepreneurship records that the rate of women entrepreneurship rose by $6 \%$ worldwide in the last two years. Research agenda of social science scholars show that women entrepreneurs are newcomers to the field. Their attention has been drawn to studies on women business owners only during the past two or three decades. When a woman or a group of women take the initiative to establish and operate a business it is referred to as women entrepreneurship (Ahmad, 2013).

\section{Business Performance}

The ability to create job opportunities and gain wealth through the business that was set up is known as business performance. It also contains the upkeep of business viability and sustainability (Garson, 2012). The total quality of activities and processes done by women entrepreneurs in managing their enterprises generate a higher profit (Mwania, 2015). "The operational ability to meet the desires of the company's major shareholders" is the definition of business performance in general (Chye, 2012).

The concept of business performance of Global Entrepreneurship Monitor (GEM) identified the successful entrepreneurs as those who achieved 3 main goals which were key performance business indicators namely; business growth or the growth of current employees, export growth and innovation growth (Brush, 2012). Hisrich, (1997) stated that five dimensions of revenue, profits, ability to face competition, business expansion and business achievements can be used to measure the performance of a particular business. Normally, profit, revenue, the number of employees, and personal income of the women entrepreneurs are considered to measure business performance (Hisrich, 1997). Further few more dimensions like Profitability (Adu, 2016; Mokhtar, 2017) as financial methods and Customer Satisfaction (Anwar \& Rashid, 2011); and Employee Satisfaction (Erogul, \& Quagrainie, 2017). as non-finance methods assisted in measuring the Business Performance (Adu, 2016).

\section{Profitability of the Business as Financial Method}

Profitability is important for continuing or growing business earnings by giving careful attention to cost control, pricing policy, sales volume, stock management, and capital expenditure. When the cost of goods sold and selling, general and administrative expenses is deducted from firm's revenue the result is net operating profits (also known as earnings). Taxes and interest are also subtracted to reach this net figure (The Nation, 2013).

The financial position of the firm is determined by the profitability which is regarded as one of the commonly used crucial indicators. When profitability is descending or if the profitability is weak in comparison to other firms in the industry, the particular firm is considered financially weak. It measures the effectiveness and efficiency of the business venture in operational condition. The performance of the organization is measured through dimensions of total profitability, cash flow, cash position and sales growth (Sunday Observer, 2013). It would be appropriate to measure the success of small and medium enterprises using employment growth, sales growth and increase in profitability, as it will be useful for policymakers (The world bank, 2011). However, Profitability generally measures the individual performance of businesses. Profitability serves as an ultimate goal for any business venture and it is known to be the ability to make benefits (Adu Emmanuel, 2016).

\section{Business Growth as Financial Method}

Business Growth can be considered as a particular stage where the business becomes suitable for expansion and looks for extra possibilities to make more profit. Business lifecycle, industry growth trend and the owner's desire for equity value creation are the functions of business growth. Business growth is explained as an increase in financial outcome, productivity, and the number of employees (Vossenberg, 2013). The performance is measured by the growth venture consisting of sales growth, the growth of the company's assets, and profit growth (Wickramasinghe, 2000). Further change in employees, market share growth, change in net income margin, change in $\mathrm{CEO} /$ owner, compensation, change in labor expense to revenue, job generation, company births, change in present value, number of acquisitions, change in pre-tax profit, and loan growth are some of the indicators that measures the business growth in research studies (United National University, 2013).

\section{Customer Satisfaction as Non-Finance Method}

Customer Satisfaction is explained as a person's feeling of liking or displeasure resulting from a person's perceived performance of a product, compared to his/her expectations (Kotler \& Keller 2006). A set of visible actions in relation to the product or service are referred to as customer satisfaction and perception of quality, which are summarized tags (Garson, 2012). Many scholars acknowledged customer 
satisfaction aspect in different perspectives (Kuraniawan, 2010). These researchers used customer retention, customer loyalty, purchasing power as indicators in their studies (Erogul, \& Quagrainie, 2017). Customer satisfaction, employee's growth and sales growth generally signifies financial performance (Anwar, \& Rashid, 2011).

\section{Employee Satisfaction as Non-Finance Method}

Investments in human resources practices can lead to employees' satisfaction. Well-defined job descriptions, investment in training, career plans and good bonus policies are valuable components of this aspect. (Akanji, 2006). All these factors influence the performance of women entrepreneurs in diverse ways. the Entrepreneurial drive of a person combined with encouragement from family and environment along with institutional support such as training, credit, marketing and consultancy services can lead to improved entrepreneurial performance among Sri Lankan entrepreneurs.

\section{Factors for Business Performance of Women Entrepreneurship}

It is evident that family support and social networking, government support, business background of their respective families but not education for their career in business and entrepreneurial family back- ground are important factors affecting business performance of women entrepreneurship (Siddiqui, 2012). When a business enters into macro business environment, it can influence the performance of that venture, while the rate of influence depends on the share of the firms contribution to the overall economy (Secretariat for Senior Ministers Government of Sri Lanka , 2012). Gender inequality existing in the developing countries, allows men to get special treatment at the expense of women. Although, provision of education and health protection for women, has benefitted women entrepreneurs in many progressive transitional economies, political and economic opportunities remained limited for them. In order to enable female entrepreneurs to have better economic options and to convert their businesses into modest enterprises to generate income and employment through improved production, intensive efforts are required (International Labour Organization and Asian Development Bank, 2011). A group of women who originate, organize and commence a business enterprise is referred to as women entrepreneurs in a previous study. These studies surfaced many specific issues in their related studies as shown in the literature. A similar study pointed out that the factors involved with the business performance are entrepreneurial orientation, human capital, entrepreneurs goals and motives, industry (SMES) characteristics, economics factors, socio-culture factors and legal and administrative issues (Fatima, Hasan and Almubarak, 2016). Adu (2016) expressed the view that macro external factors, industry factors and competitors and market are important. Pooja Jha and Munish Makkad, Sanjiv Mittal (2019) highlighted the significance of components such as financial, networking, business environment, training and motivation. Anwar, \& Rashid, (2011) claimed that the impact of personal characteristics, ability and financial support skills can be used to explain the business performance. Mwania (2015) deliberated that entrepreneurial training, business network, financial accessibility and domestic commitment to be the factors influencing performance of women entrepreneurs. Hence the researcher selected domestic commitment, financial capabilities and network affiliation as the independent variables in order to measure the business performance of women entrepreneurs giving due consideration to the available literature, since those are the factors which were commonly used by previous researchers.

\section{Domestic Commitment as a Factor of Performance}

Female entrepreneurs have their domestic obligations such as children caring, washing clothes and cooking foods and due to these women entrepreneurs do not have much time to manage ventures (Mwania, 2015). These domestic tasks make them face difficulties and sometimes they have to close their own business to attend to the other needs. Especially, married women entrepreneurs have to balance business and domestic work properly, and success of their business depends on family support. In the current scenario, women engage in various types of domestic work.

Several studies conducted around the globe enlighten on the financial factors affecting women entrepreneurs (Akanji, 2006). Generally, women get exhausted and very often dejected on looking for funds from financial institutions since they believe that their loan applications will be rejected. Therefore, women become to disheartened borrowers and it reduces the rate of start-up businesses of women (Chye, 2012).

\section{Access to Finance}

Financial assistance of some sort is needed by entrepreneurs to start their businesses, and it could be either a formal bank loan or money from a savings account. Women in developing countries do not have much access to funds, since they are concentrated in poor rural communities with few opportunities to borrow finances (Chye, 2012). Insufficient finances pose problems to run a business, and sometimes cause delays on business growth due to lack of proper financing available (Dharmaratne, 2012). The complicated "assistance" of support agencies make many women entrepreneurs to experience difficulties. Therefore, incapability to keep proper records, the difficulty to separate business operations from personal, manage cash flow and growth are the issues that affect business growth of SMEs (Erogul, \& Quagrainie, 2017). The thought that financial institutions will rejected women's loan applications can lead the women to be discouraged when seeking funds. So ultimately women are become to discourage are deals with various aspects of the performance of the business. However, economic requirement is connected with profitability while achievement strongly linked with income level of the business and independence correlate with revenue. 


\section{Network Affiliation}

Entrepreneurship is surrounded by a complex network of social relationships, which is stated by network affiliation. Linkages between ambitious entrepreneurs, resources, and opportunities that exist within these networks, facilitate or sometimes inhibit entrepreneurship (Ahmad, Ramayah, Wilson.\& Kummerow, 2010). However it has been revealed that networks indicate positive effect on business profitability with good potentials of economic development (Ahmad, Ramayah, Wilson.\& Kummerow, 2010).

An individual belongs many social groups to this area. The entrepreneur too can belong to diverse social groups such as the family, work group, community association and religious groups that consist of a wide network range. It has been revealed that while men occupy a wider network diversity, women possess more network ties than them. Such broader networks assist them to access credit and market information faster than women (Frost, 2018).

\section{Methodology}

The philosophical foundation of the research is examined and the manner in which methodology was based on this is discussed. It is also deliberated the relevant type of the study, research approach, research strategy, research setting and time of the study. Further the unit of analysis, population, sample, sampling technique and the sampling framework are elaborated under population and sampling. The other main consideration that are explained, consist of data collection methods, validity and reliability measures, methods of measurements, data analysis and synthesis and ethical.

\section{The Conceptual Model}

The research variables were defined by the researcher and the conceptual framework was formulated, based on those research variables, with due attention to the available literature. Since the researcher developed this conceptual framework, it is a self-developed model and this will provide the basic structure or the foundation to the entire study. The research variables were defined by the researcher, and the conceptual framework was based on those research variables. The factors of women entrepreneurs comprise the independent variable of this study. Domestic commitment (DC), financial capabilities (FC) and network affiliation (NA) are the three individual factors that comprise the independent variable. Domestic commitment refers to the work female entrepreneurs must conduct including children caring, washing clothes and cooking food which are the causes women entrepreneurs do not have sufficient time to manage their venture (Mwania, 2015). Move over, they come across difficulties due to these domestic errands, compelling to close their own business. Married female entrepreneurs need to balance their business and domestic responsibilities. Hence family support is a key factor in managing their business successfully. Financial capability is the ability to manage the finances and use financial services in th most appropriate manner to meet the needs and the prevalent social and economic situations (Man, \& Wafa, 2008). Many factors affect the financial capabilities. However, for the purpose of this article, Domestic Commitment, Financial Capability and Networking Affiliation are selected.

Network Affiliation relates to building up social networks and relationships by an individual person. Furthermore, this can be measured by using the number of networks as a measurement. These include service of advisors, memberships in associations etc. Numerous factors that are affected the network affiliation and the number of network (Hisrich, 1989) and interaction (Dharmaratne, 2012) are selected for this study. Dependent variable of the study is business performance, which cannot be simply defined by a single operational measure. The multidimensionality of performance is acknowledged exposing the strain on measuring business performance (Mitchelmore, \& Rowley, 2010). Many aspects contribute to the measure of business performance, and financial and non-financial components are selected for this thesis. Profitability (Adu, 2016) and business growth (Mokhtar, 2017) are used to measure business performance of women entrepreneurs, as financial measurements. Since most of the women entrepreneurs businesses belong to very small category non - financial method is to selected carefully. Therefore, customer satisfaction (Kuraniawan, 2010) and employee satisfaction are selected to represent a non-financial measurement for this study. Based on the information the conceptual model is presented in the figure 1.

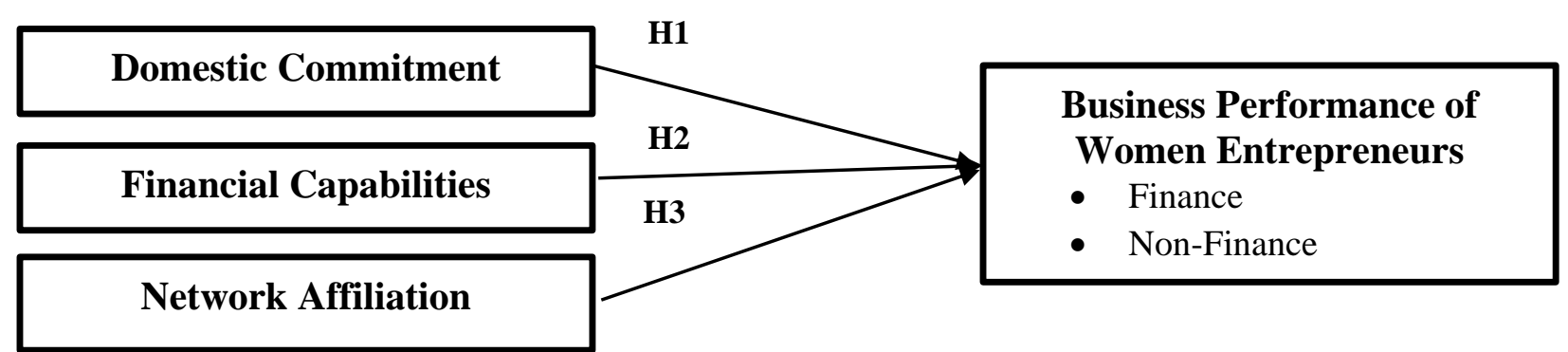

Figure 1: Conceptual Model of the Study

(Source: Mwania, 2015 ) 
Based on this conceptual framework, research has derived the relevant hypotheses.

\section{Research Objective 01}

To find whether there is an impact of Entrepreneurial Competencies on Business Performance of Women Entrepreneurs in Gampaha District, Sri Lanka.

\section{Research Objective 02}

To find whether there is an impact of Financial Capabilities on Business Performance of Women Entrepreneurs in Gampaha District, Sri Lanka.

\section{Research Objective 03}

To find whether there is an impact of Network Affiliation (NA) on Business Performance of Women Entrepreneurs in Gampaha District, Sri Lanka.

\section{Research Question 01}

Is there an impact of Entrepreneurial Competencies on the Business Performance of Women Entrepreneurs in Gampaha District, Sri Lanka?

\section{Research Question 02}

Is there an impact of Financial Capabilities on the Business Performance of Women Entrepreneurs in Gampaha District, Sri Lanka?

\section{Research Question 03}

Is there an impact of Network Affiliation (NA) on the Business Performance of Women Entrepreneurs in Gampaha District, Sri Lanka?
Hypothesis 01

$\mathrm{H}_{1}$ There is an effect of Domestic

Commitment on the Business

Performance of Women

Entrepreneurs.

\section{Hypothesis 02}

$\mathrm{H}_{2}$ There is a positive relationship between Financial Capabilities (FC) and the Business Performance of Women Entrepreneurships (BP).

\section{Hypothesis 03}

$\mathrm{H}_{3}$ There is a positive relationship between Network Affiliation (NA) and the Business Performance of Women Entrepreneurships (BP).

\section{Research Design Process}

The main component of the thesis is the process of research. Hence, the research design process of the study is considered as a very important concept. Saunders, Lewis \& Thornhill (2016) presented few stages of a research study through the Onion Model. The positivist paradigm is a discipline that is characteristic and independent from personal, political or religious values as per philosophy. The reality waiting to be discovered according to positivist direction of impartiality and essential nature. The positivist looks for determining the causes and mechanisms that produce effects. Two methods are used to describe

Research Approach, which are inductive and deductive approach. Qualitative researchers, very often accept inductive approach in conducting research. Specific experience or observation are the basis of inductive research. In contrast to qualitative researchers, quantitative researchers use deductive approach. The main focus is to start working from a general to specific understanding.

Research Strategy is the use of a questionnaire tool as a survey strategy method since it enables the researcher to scrutinize and explain the influence on constructs along with cause and effect associations (Saunders et al.2016).

Research Choice shows that many methods are available to identify the research selection. These are qualitative research, quantitative research and mixed-method research. Practicing only quantitative and qualitative methods indicates the lack of the major approaches being used nowadays in the social and human sciences (Creswell 2003). Both qualitative and quantitative elements are included in the mixed method, using both primary and secondary data. This study adopts a quantitative research approach to conduct the research study. Since the objective is to obtain a general response about individual factors required for women entrepreneurs in Gampaha district, it is relevant. Research conducted by (Man \& Wafa, 2008), implemented a quantitative approach using quantitative research methods. Further a quantitative approach was applied in a study which was a key reference for this thesis (Mokhtar, 2017).

Time Horizon is the final layer. Indicates some control over the variables being studied. The research approach or methodology has no effect on time horizon (Saunders et al., 2016). Time horizon means the study could be one-shot or over a period of several days/weeks/months. It means that data collection is either done once or carried out in several points in time throughout a longer period. One shot data collection is referred to as cross- sectional while if it is conducted over a longer period of time it is known as longitudinal. The author has used the cross-sectional time horizon method for this study. Considering the time constraint, the selection has been made for this specific phenomenon at a specific time.

Data collection was conducted from a sample population, and statistical analysis techniques correlation and regression testing carried out through the SPSS version 23. This research study used the target population of all women entrepreneurs in Gampaha district, Sri Lanka. The total number of registered women entrepreneurs at the Small Enterprises Development Bureau (SED), Gampaha district, were identified as target population. The statistics provided by SED, contained 357 of women entrepreneurs who have registered there up to now. Therefore, the unit of study is an individual women entrepreneur who had a registered business at SED Bureau, with special reference to Gampaha district, Sri Lanka. The researcher in addition, implemented the non-probability sampling method to overcome the difficulties arise in randomization of selecting the sample from the population and the time limitations. Hence, the women entrepreneurs were selected by convenient sampling method. A total of 185 questionnaires were distributed among the units of the sample while the non-response amount was 5 and 180 completed questionnaires were collected. 


\section{WRITE DOWN YOUR STUDIES AND FINDINGS}

\section{Analysis of Data}

Although the main purpose of the study is to achieve specific objectives of this study, three research questions would be dealt with, to search resolutions. The first is whether there is an impact of entrepreneurial competencies on the business performance of women entrepreneurs in Gampaha district, Sri Lanka. Secondly it is to determine whether there is an impact of financial capabilities on the business performance of women entrepreneurs. The final question is to find out if there is an impact of network affiliation on the business performance of women entrepreneurs.Descriptive analysis was implemented along with the univariate analysis order to summarize the data by using the frequency analysis. Construct reliability indicates the manner which various items under each variable relate to each other as a set. Convergent validity shows the ability of the data collecting instrument (questionnaire) to measure, as it should perform. The two types of validity that exists are face validity and content validity. "Face validity is a subjective judgment on the operationalization of a construct" (Saunders, 2016).

The adequacy of the sample mainly ensured by KMO value and according to this study all the variables show values greater than 0.808 for KMO. Furthermore, BP has a maximum factor loading of 0.861 and minimum factor loading of 0.744 . DC indicates a maximum factor loading of 0.837 and minimum factor loading of 0.729. A maximum factor loading of 0.959 and minimum factor loading of 0.721 is demonstrated by FC while NA has a maximum factor loading of 0.850 and minimum factor loading of 0.763 . The Bartlett's Test of Sphericity display Sig. value less than 0.05 for all variables. This research study analysis did not exhibit any outliers. "A common rule-of-thumb test for normality is to run descriptive statistics to get skewness and kurtosis, and then divide these by the standard errors" (Garson. 2012). The mean of responses were obtained for each variables in the questionnaire survey. The values of all the variables were within the range of 3.0472 to 3.4028. which indicates that almost all the responses recorded neutral. BP has a mean value of 3.0693 indicating neutral responses and it was the highest mean value generated from the data analysis. The lowest mean value recorded was 3.0472 for the independent variables of financial capabilities. It demonstrates that many respondents answered between the neutral and disagree response for the questions listed under that particular variable. P-p plots, scatterplots, ANOVA tables and model summaries could be used to test linearity This research made use of p-p plots, ANOVA tables and model summaries (R2) to test linearity for each independent variables with the dependent variable. R Square values recorded $0.478,0.505$ and 0.493 for DC, FC and NA respectively. The results revealed the expected values of the decision criteria demonstrated less than $\mathrm{P}<0.05$ of ANOVA values as 0.000 .

"Multi-collinearity is the occurrence of high inter-correlation among independent variables in a multiple regression model". "As a rule of thumb, inter-correlation among the independents above 0.8 signals a possible problem" (Garson, 2012). Thus, it shows that the multi-collinearity level is good if it is lower than 0.8 . However, this value may vary from researcher to researcher. In order to find out the relationship between the dependent variable and the independent variables, the correlation analysis can be done. The correlation analysis for this study was done by the parametric analysis and Pearson correlation method as normally distributed residuals exist in the model of the study. The results of this study, show positive relationships between all the independent variables (DC, FC, $\mathrm{NA}$ ) and the dependent variable (BP) at the significance level of 0.01 (2-tailed test). The results of correlation analysis illustrate a strong positive relationship between DC and BP exists with the correlation coefficient of 0.691 at a significant level of $99 \%$ ( $\mathrm{p}=0.000$ ). Likewise, a strong positive relationship is observed between FC and BP with the correlation coefficient of 0.711 at $99 \%$ significant level $(p=0.000)$. Furthermore, the relationship between NA and BP demonstrates to be strong and positive with the correlation coefficient of 0.702 at a significant level of $99 \%(\mathrm{p}=0.000)$. Hence, the results reveal that the increase of DC, FC and NA enhances the BP of respondents of this study. The hypotheses testing is the most vital procedure in a statistical test. A hypothesis test scrutinizes using sample data, whether two mutually exclusive statements about the population are supported by the literature. Assumptions for the population could only be achieved by testing hypotheses.

Regression analysis consists of a set of some tests that assist to measure or estimates the relationship among variables. The square root of R-Square is denoted by $\mathrm{R}$ and is the correlation between the observed and predicted values of dependent variable. Higher R-Square serves better, which indicates that data are closely fitted to the regression line. Further, it specifies that the model include a higher variability of the response data around its mean. The study has a total R-Square value of $61 \%$. Coefficients table is presented in the table 2 as follows.

Table 2: Coefficients values of the Study

\begin{tabular}{|c|c|c|c|c|c|c|c|c|}
\hline \multirow[b]{2}{*}{ Model } & & \multicolumn{2}{|c|}{ Unstandardized Coefficients } & \multicolumn{2}{|l|}{$\begin{array}{l}\text { Standardized } \\
\text { Coefficients }\end{array}$} & \multirow[b]{2}{*}{ Sig. } & \multicolumn{2}{|c|}{ Collinearity Statistics } \\
\hline & & $\mathrm{B}$ & Std. Error & Beta & $\mathrm{T}$ & & Tolerance & VIF \\
\hline \multirow[t]{4}{*}{1} & (Constant) & .253 & .176 & & 1.439 & .125 & & \\
\hline & $\mathrm{DC}$ & .225 & .072 & .232 & 3.122 & .002 & .394 & 2.540 \\
\hline & $\mathrm{FC}$ & .393 & .079 & .345 & 4.943 & .000 & .448 & 2.232 \\
\hline & NA & .278 & .067 & .300 & 4.159 & .000 & .419 & 2.389 \\
\hline
\end{tabular}

a. Dependent Variable: BP 
$\mathrm{R} 2=0.616, \mathrm{~F}=94.256$ and 'P-value' $<0.05$ was obtained through the multiple regression model with three predictors. The relationship between variables were explained by the standardized coefficients (beta values). The table shows that DC, FC and NA have significant positive regression weights, depicting that respondents with higher scales on these variables tend to have higher BP. Since values less than 0.05 were obtained for the 'p-value' for coefficients of all variables, the relationship is significant. The overall quality of the prediction is shown by $\mathrm{R}^{2}$ and the $\mathrm{R}^{2}$ values in table express that the model has a majority (more than 50 percent) of the total variance. A 60.6 percent of the total variance is explained by BP DC, FC, and NA together. Further, independent variables are significant at 95\% of the confidence level as indicated by all the values. Hence, this table demonstrates that all the hypotheses are supported by the analysis.

The results of Pearson's correlation analysis provides a value of 0.691 , which is significant at $99 \%$ ( $<<0.01$ ) for the correlation coefficient ( $\mathrm{r}$ ) between domestic commitment and business performance of women entrepreneurs in Gampaha district. Therefore, the hypothesis that there is a significant relationship between DC and BP is supported by the data. Further, a moderate positive relationship can be identified. The correlation coefficient ( $r$ ) between financial capabilities and business performance of women entrepreneurs is 0.711 , which is significant at $99 \%(\mathrm{p}<0.01)$ as per the results of Pearson's correlation analysis. Therefore, the null hypothesis can be rejected while the alternative hypothesis is not rejected. The data support the hypothesis indicating a significant relationship between FC and BP and it is identified as a strong positive relationship. Network affiliation shows an impact on business performance. The correlation coefficient ( $\mathrm{r}$ ) between network affiliation and business performance is 0.702 , which is significant at $99 \%$ ( $\mathrm{p}<0.01$ ) according to the results of Pearson's correlation analysis. A significant relationship between NA and BP can be observed as the data support the hypotheses and the relationship is identified as a moderate positive relationship.

\section{Discussion}

The main objective of the study is to determine the impact of individual factors on the business performance of women entrepreneurs. The literature given in chapter two specifies the main variables that pronounce individual factors which are DC, FC, and NA. The research study has the first objective which is to investigate the impact of domestic commitments on business performance among women entrepreneurs in Gampaha district, Sri Lanka. The developed alternative hypothesis is supported by facts and it proves the impact of entrepreneurial competencies on business performance. This is confirmed by the Pearson correlation coefficient is 0.691 with 'p-value' $<0.01$ and at a 0.000 significant level and all the values were gained by conducting the 2-tailed test. It signifies a statistically significant strong positive correlation between EC and BP. Hence, the relationship between DC and BP is fully supported by the empirical results of the study (Mwania, 2015). Further, DC shows a significant impact on BP over the other factors in women entrepreneurs in Gampaha district, Sri Lanka. In addition, DC of the selected sample of women entrepreneurs had average level of its Mean as 3.4028 and the Standard Deviation as 0.82592 from descriptive statistics which reflects the average value of DC, vary between 2.57688 (3.4028-0.82592) and 5.30859 (3.4028+0.82592). This is a slight deviation from the midpoint of 3 and 6. Therefore, it is evident that the sample of women entrepreneurs in Gampaha district have average domestic commitments. Many empirical evidence which support the present study can be found in comparing the findings of this study with the previous findings. Scatter plot, indicates a positive relationship between EC and BP with a correlation coefficient, $r=0.691$ which is more than 0.3. The ANOVA table shows Fvalue is 162.973 and degrees of freedom are 1 and 178. P-value or the probability of type 1 error is less than 0.001 . Since a F-value, with a smaller P-value (<0.05), suggests that BP depends on EC. The coefficient of determination, $\mathrm{R}^{2}$ is 0.478 and $47.8 \%$ of the variation in BP can be explained by EC. The Regression equation explains the unit increase in EC. Furthermore, VIF value for all variables are less than 10(VIF>10) which signifies that there is no multicollinearity issue existing in the model.

Many empirical evidence of previous research that supports the present study, can be identified. The diagnostics procedure done case wise, did not distinguish any outliers and the test of normality showed that the residual could be assumed to be normal. Consequently, the conclusion can be that DC has an impact on BP. Business enterprises in a country affect their economies and DC plays an important role in managing a business efficiently. Organizations depend on entrepreneurs who perform multitasks to a great extent, demonstrating they provide an essential connection to the economy while their efficient management is the primary factor responsible for a resourceful output for the economy at large. Hence, the studies have shown the positive impact of DC on BP.

Discussion of the Second Sub Objective of the Study. The aim is to examine the impact of financial capabilities on business performance among women entrepreneurs in Gampaha district, Sri Lanka. The developed alternative hypothesis is supported by the facts to indicate the impact of financial capabilities on business performance. The Pearson correlation coefficient obtained was 0.711 with 'p-value' $<0.01$ and at a 0.000 significant level while all the values resulted by conducting the 2-tailed test. A statistically significant strong positive correlation between FC and BP is detected. Consequently, the association between FC and BP were in total agreement with the empirical results of the study.

Additionally, FC has a significant influence on BP over the other factors, among women entrepreneurs in Gampaha district. Moreover, for the FC of the selected sample, the descriptive statistics average level obtained its Mean as 3.0472 and the Standard Deviation as 0.70166 . This signifies that the average value of FC in women entrepreneurs under the study, vary between 2.34554 (3.0472-0.70166) and 3.117366 (3.0472-0.70166). There is a slight deviation from the midpoint of 3 and 4 which leads to conclude that the sample of this study has average financial capabilities. Many previous empirical findings could be detected that support the present study. Scatter plot, indicates a positive link between FC and BP while the correlation coefficient, $\mathrm{r}=0.950$ which is more than 0.3 . The ANOVA table gives a F-value of 181.901 and degrees of freedom are 1 and 178. Further, the probability of type 1 error or the P-value is lower than 0.001. Accordingly, larger F-value along with a smaller P-value $(<0.05)$, indicates that FC has an impact on BP. The coefficient of determination $\mathrm{R}^{2}$ is 0.505 and $50.5 \%$ of the variation in BP can be described by FC. The Regression equation explained

This publication is licensed under Creative Commons Attribution CC BY

http://dx.doi.org/10.29322/IJSRP.11.07.2021.p11539

WWW.ijsrp.org 
the unit increase in FC. Since, VIF value for all variables are less than 10(VIF>10) it denotes that no multicollinearity issues exist in relation to model. In comparing this study with previous empirical findings, many evidence that support the present results could be found. Furthermore, any outliers were not detected at the case wise diagnostics procedure and the test of normality signifies that the residual can be assumed to be normal. Thus, it can be concluded that FC has an impact on BP. These findings of the study can be proved in comparing the previous findings of the researches. (Bruno \& Tybjee, 1982) detected that a relationship exists between economics factors like venture capital, loan availability, credit facilities and related services which have an impact on the business performance. Henceforth, it can be concluded previous literature supports the findings of this research study.

Discussion of the Third Sub Objective of the Study. The purpose of the study is to consider the impact of network affiliation on business performance among women entrepreneurs in Gampaha district, Sri Lanka. The developed alternative hypothesis is supported by facts showing the impact of network affiliation on business performance. The Pearson correlation coefficient obtained was 0.702 with ' $p$-value' $<0.01$ and at a 0.000 significant level where all the values were as a result of the 2-tailed test. It specifies that there is a statistically significant strong positive correlation between NA and BP. Therefore, the empirical results of the study totally agreed with the relationship between NA and BP. Further, NA affects BP among women entrepreneurs in Gampaha district significantly, over the other factors.

NA of the selected sample of women entrepreneurs had descriptive statistics at average level since its Mean was 3.0694 and the Standard Deviation was 0.8626 which reflects the average value of NA among them vary between 2.2068 (3.0694-0.8626) and 3.15566 (3.0694+0.8626). This shows a slight deviation from the midpoint of 3 and 4. Hence, it can be seen that the sample consists of women entrepreneurs who have average network affiliation. Examining the previous research, led to detecting many empirical evidence that support these findings. The scatter plot, indicates a positive association between NA and BP. The correlation coefficient, $\mathrm{r}=0.702$ which is greater than 0.3, while the ANOVA table indicates a F-value as 172.909 and the degrees of freedom are 1 and 178 . The Pvalue or the probability of type 1 error is less than 0.001 . Since, larger F-value, with a smaller P-value $(<0.05)$, implies that BP depends on NA. The coefficient of determination, $\mathrm{R}^{2}$ is 0.493 and $49.3 \%$ of the variation of BP can be described by EC. Then every unit increase in NA is explained by Regression equation. Furthermore, VIF values for all variables indicate lower than 10(VIF>10) showing no multicollinearity issues regarding model.

Many empirical evidence which supported the present study could be found among the previous research. Besides, diagnostics procedure done case wise, did not show any outliers while the test of normality revealed that the residual can be assumed to be normal. Hence, the conclusion can be that there is an impact of NA on BP. Garson (2012), viewed that entrepreneurship is rooted in a complex network of social relationships. However, the research carried out in the Sri Lankan context are not compatible with this finding as many of the Sri Lankan women entrepreneurs are unenthusiastic in joining social networks mainly due to time constraint. However, the present study agrees with the finding of the said research that these networks facilitate entrepreneurship or constrained by linkages between aspiring entrepreneurs, resources and opportunities. Anyhow, the presence or absence of networks in the form of membership in associations has an influence on performance (Dharmarathne, 2012). Hence, the conclusion of this research study is supported by the previous literature in this field. Therefore, as per the above discussion, the relationship between the independent variables and the dependent variable can be summarized as follows.

\section{H1: There is an impact of Domestic Commitment on Business Performance - Supported. \\ H2: There is an impact of Financial Capabilities on Business Performance - Supported. \\ H3: There is an impact of Network Affiliation on Business Performance - Supported.}

Based on the level of significance of the variables, the factors influencing the business performance in women entrepreneurs in Gampaha district, could be ranked according to their strength of impact and the order is FC, NA and DC respectively.

\section{CONCLUSION}

Around the world, economic development of a country is the most significant and major requirement for every nation. The people in developed countries enjoy a high level of living standards among enhanced quality of life. Entrepreneurship is considered as a leading factor required for a sustainable economic development, especially for a developing country like Sri Lanka. Likewise, it is considered as a capable tool when competing with developed countries as it enables to look for new opportunities, to be innovative and also wealth creation through in order to elevate the living standards of the individuals of the country. Entrepreneurship serves as a reliable solution for numerous economic issues such as unemployment, under-development, and poverty. Besides, entrepreneurship is an actual timely resolution for many of the existing economic problems in the country such as income disparity, high unemployment rate etc. Hence, empowering entrepreneurs has become a major timely necessity.

Nevertheless, in developing countries the failure rates of women entrepreneurs are very high and the same situation is seen in Sri Lanka too. Entrepreneurship is not considered to be an attractive career choice by the Sri Lankans although they are more attracted to jobs. However, when driving the country towards sustainable economic development, individual factors of women entrepreneurs in the country are critical issues, which should be taken into consideration. Especially, taking suitable precautions for individual factors among women entrepreneurs of the country is more crucial under the circumstances as they are the essence of the most contributed parties for the country. It is important to look into individual factors to overcome any issues mentioned in above. This study was carried out with the objective of determining the impact of the factors of women entrepreneurs in Gampaha district with a sample of 185

This publication is licensed under Creative Commons Attribution CC BY.

http://dx.doi.org/10.29322/IJSRP.11.07.2021.p11539

WWW.ijsrp.org 
entrepreneurs registered in Small Enterprise Development (SED) Bureau in Gampaha district Sri Lanka. The objectives derived for the research study are to identify the individual impacts of DC, FA and NA on BP separately. The findings of the study revealed that a positive significant relationship exists between business performance and domestic commitment. Further, a similar kind of relationship is signified between business performance and financial capabilities and network affiliation. When the results of the relationships of the variables influence on BP were ranked according to their highest significance, the order was FA, NA and DC.

The enrichment of the BP of women entrepreneurs are to be improved with recommendations for resolving the issues raised by few factors. By focusing on the results achieved from the study, DC is a variable which has a positive impact on the BP of women entrepreneurs. It basically shows that if women entrepreneur can improve on her DC it will help to increase the BP ultimately. Therefore, in order to improve DC of women entrepreneurs, some recommendations can be made in the Sri Lankan context while giving due consideration to the previous recommendations given by the earlier scholars. Garson (2012), believes in establishing industrial or business centers especially for women entrepreneurs in order to balance their life in relation to domestic commitment, financial capabilities, industrial experience as well as network affiliation. It is evident that women entrepreneurs can obtain training and development facilities, networking and communication through this type of industrial and business centers. Another very vital aspect is enhancing the accessibilities to finance for the women entrepreneurs. Strategies such as developing authorized loan portfolios for female entrepreneurs through bank branches would be helpful in implementing this idea while providing gender sensitive training in banking practices to the bank managers and loan officers to eradicate any gender discriminations when women entrepreneurs apply for finance (Global Entrepreneurship and Development Institute, 2013). The awareness on loan facilities and micro credit facilities among women entrepreneurs should be enhanced since this study highlights a lack of knowledge and awareness in terms of those facilities among this category. The government can directly get involved in this exercise with financial institutions to organize sessions, programs, and workshops to improve the financial literacy of the women entrepreneurs (Hemalatha, 2005). Furthermore, women entrepreneurs can get benefitted from mentoring and business development support services. The available literature highlights that many of the women owned business ventures earn low profits and show lower performances, mainly due to lack of mentorship, advisory and business development support services. Government and other relevant authorities need to take an interest in this and provide required services to uplift the status of women entrepreneurs (Global Entrepreneurship and Development Institute, 2013). A further recommendation is to provide convenient network affiliation which is vital to the women entrepreneurs. This is an essential need as having a powerful contact is always encouraging women to involve with entrepreneurship and business activities more efficiently (Global Entrepreneurship and Development Institute, 2013).

\section{Implications}

Findings of the study reveals that business performance among women entrepreneurs in Gampaha district, Sri Lanka, is positively influenced by DC, FC, and NA. Sri Lanka is still considered as a developing country and heading towards an economic development and sustainable growth. The country is facing many critical issues with growing unemployment rates while self-employment is an appropriate solution. Available literature reveals that entrepreneurship could provide better resolutions for economic issues such as inequality in income distribution, high rate of unemployment, utilizing the natural resources etc. Additionally, attitudes regarding entrepreneurial competencies should be enhanced in relation to educators, potential or existing entrepreneurs who are in the business sectors and policymakers. These segments of society could get involved by being more alert in facilitating the business performance of women entrepreneurs in numerous ways. Specifically, the existing entrepreneurs and potential entrepreneurs in the business sector can identify the strengths and weaknesses in this sector. Based on these findings for Gampaha district women entrepreneurs, any individual factors relevant to other parts of the country too can be identified.

Another aspect would be to improve the entrepreneurship education by initiating entrepreneurship education programs, relevant training programs with the objective of enhancing the performance of female entrepreneurs. Institutions that offer entrepreneurship training programs will be benefitted from this effort since they can have a much better selection during enrolling the candidates for their programs. As the research findings concluded, it was observed that many of the married female entrepreneurs did not get much support from their husbands and family members. Therefore, the government and other relevant authorities can promote the entrepreneurial culture in Sri Lanka, to create awareness about entrepreneurship, in order to overcome this situation. These activities will lead their family members to understand the importance of supporting the women entrepreneurs to perform successfully in their business without barriers and challenges from the family. Finally, a better guidance is provided for future research by the present framework of the study, and the findings will give the relevant awareness in empowering the women entrepreneurs in the Sri Lankan context. The major fact in this regard is the contribution of women is vital for the economic prosperity of the country.

\section{Further Studies and Limitations of the Study}

Although a large number of individual factors influence business performance, this research measured only three selected variables. It is not easy to address all the factors which influence entrepreneurial process in a single study as the entrepreneurial process is very complex. Hence the researcher limited the evaluation to DC, FC, and NA from among a huge number of individual factors. Some of these other factors can be identified as motivational goals, human capital, and environmental influence etc. The present study will lead future researchers as a guideline to above mentioned factors, although those factors could not be included in this evaluation. 
Furthermore, financial and non-financial perspectives were utilized to measure the dependent variable (BP), using profitability of the business, business growth, customer satisfaction and employee satisfaction of the business organization. However, there are many other financial and non-financial measurements which can be used for this purpose such as the ability to face competition, innovations, etc. Due to the difficulties in accessing the whole population, a sample of 180 respondents were selected for this study. However, a bigger sample would have resulted in more accurate data. Further, a random sampling technique was used for the group where all possible women entrepreneurs in the Gampaha district can be represented, without applying convenience sampling technique. The research scope was limited to the women entrepreneurs in Gampaha district. Hence it is open for any researcher to expand the scope of the study into another area or can select another population and sample to carry out the research.

•

[1] Adu, E. A. (2016), 'The Impact of External Environment Factors on Performance of Small \& Medium Sized Enterprises in the Pharmaceutical Industry in Kumasi Metropolis'.

[2] Ahmad, N.H., Ramayah, T., Wilson.\& Kummerow, L. (2010). Is Entrepreneurial Competency and Business Success Relationship Contingent Upon Business Environment? A Study of Malaysian SMEs, International Journal of Entrepreneurial Behaviour \&Research, 16(3), 182-203

[3] Ahmad, S. Z. (2013). 'The Need for Inclusion of Entrepreneurship Education in Malaysia Lower and Higher Learning Institutions.' Education and Training, 55(2), 191-203.

[4] Akanji, O. (2006). Microfinance as a strategy for poverty reduction. Central Bank of Nigeria Economic and Financial Review, 39 (4).

[5] Anthony Mwania (2015), Factors Influencing the Performance of Women Entrepreneurial Ventures in Kongowea Market, Mombasa County, Kenya

[6] Anwar, M. U., \& Rashid, A. G. (2011). Female Entrepreneurs-A Review of the Literature and Proposed Conceptual Framework. In Proceedings of 2nd International Conference on Business Management [Online] Available at: www. umt. edu. pk/icobm2012/pdf/2C-78P. pdf, accessed (July 7th , 2018).

[7] Brush, C., \& Hisrich, R. D. (1999). Women-owned businesses: Why do they matter? In Z. J. Acs (Ed.), Are Small Firms Important? Their Role and Impact: 111-127. Boston, MA: Kluwer Academic Publisher.

[8] Brush, C.G. (2012). Research on women business owners: Past trends, a new perspective, and future directions. Entrepreneurship Theory and Practice 16(4): 5-30.

[9] Chye, L. T. (2012). 'Entrepreneurial Orientation and Managerial Competence: Are they Complementary or Contradictory to SME Performance in Malaysia?' (Doctor of Business Administration), the University of Newcastle, Australia, Newcastle, Australia.

[10] Dharmaratne, K. L. B. G., 2012, 'Impact of Individual Factors on the Business Performance of Women Entrepreneurs in Sri Lanka', Sabaragamuwa University Journal, vol. 11, pp. 139-165

[11] Erogul, M. S., \& Quagrainie, F. A. (2017). Motivation, Networking and Business Growth: Perspectives of Ghanaian Female Entrepreneurs. Journal of Enterprising Culture, 25(03), 297-316.

[12] Fathima, S. M. A. Hasan and Muneer Mahomed (2016), "Factors influencing women entrepreneurs performance in SME", Ahlia university ,manama , Bahrain

[13] Food and Agriculture Organization of the United Nations (2013), “The Female Face of Farming”, http://www.fao. org/gender/infographic/en/ [accessed on 1st May 2013]

[14] Frost, J. (2018). How to interpret R-squared in Regression analysis. Retrieved 3 5, 2019, from https //statisticsbyjim, com/ regression/interpret- r-squared- regression/

[15] Gamage, A. (2003), Small and Medium Enterprise Development in Sri Lanka: A Review http://202.11.2.113/SEBM /ronso/no3_4/aruna.pdf [accessed on 2nd November 2013]. 
[16] Garson, G.D. (2012). Testing statistical assumptions. Statistical associates publishing.

[17] Global Entrepreneurship and Development Institute (2013), The Gender Global Entrepreneurship and Development Index (GEDI), http://i.dell.com/sites/discontent/corporate/secure/en/Documents/Gender_GEDI_Executive_Report.pdf [accessed on 14 March 2014].

[18] Government of Sri Lanka, Sri Lanka (2019), The Emerging Wonder of Asia: Mahinda Chintana Vision for the Future

[19] Hemalatha, S. (2005). Women in local politics: A study of women's participation in the politics of Sabaragamuwa province from 1987 to 2005 , an unpublished document

[20] Hisrich (1997). Networking among women entrepreneurs. In O. Hagan, C. Rivchun, and D. Sexton, eds, Women-Owned Businesses. New York: Praeger, pp. 103-132.

[21] K.L.B.G D Dharmarathna, (2012), "Impact of individual factors on the business performance of women entrepreneurs in Srilanka".

[22] Malaya, M. (2006), A Gender-based Analysis of Performance of Small and Medium Printing Firms in Metro Manila .Journal of International Women's Studies Vol. 8 \#1 (13-15)

[23] Man, M.M.K. \& Wafa, S.A (2008). 'Distinctive Capabilities and Performance of Small and Medium Size Enterprises (SMEs) in Malaysia.' International Business \&Economics Research Journal, 7(6), 45-59

[24] Mitchelmore, S., \& Rowley, J. (2010). Entrepreneurial Competencies: A Literature Review and Development Agenda. International Journal of Entrepreneurial Behavior and Research, 16(2), 92-111.

[25] Mokhtar, (2017), 'A study of competencies that influence entrepreneur performance in retail business ventures in Malaysia', DBA thesis, Southern Cross University, Lismore, NSW.

[26] Nanayakkara, G. (2011), Enhancing the Capacity of Banks to Shaping Development of SMEs, Association of Professional Bankers, Sri Lanka. http://www.apbsril anka.org/general/03_articals/articals_23_ann.html [accessed on 1st November 2013].

[27] Pooja jha and, Munish Makkad (2019) ", performance oriented factors for women entrepreneurs -a scale development perspective"

[28] Ranasinghe, S. B. (2008), 'Factors Contributing to the Success of Women Entrepreneurs in Sri Lanka'.

[29] Saunders, Lewis \& Thornhill (2016) Research Methods for Business Students Fifth edition

[30] Secretariat for Senior Ministers Government of Sri Lanka (2012), National Human Resource and Employment Policy, http://apgreenjobs.ilo.org/resources/ meeting-resources/green-jobs-in-asia-regional-conference-flyer/conferencedocuments/green-jobs-projects-background-documents/green-jobs-in-asia- gja-project/sri-lanka/national-human-resourceand-employment-policy-for-Sri- Lanka-under-reviewed-by-parliament/at_download/file [accessed on 31 October 2013]

[31] Seelanathan, A. (2013), 'Participation of Family-Women in Agricultural Production: A Case Study Of Jaffna District, Sri Lanka', Journal of Economics and Sustainable Development, available at: www.iiste.org/Journals/ index.php/JEDS/article/ download/7226/7285 [accessed on 22nd February 2014].

[32] Siddiqui, A. B. (2012), 'Problems Encountered by Women Entrepreneurs in India', International Journal of Applied Research \& Studies, Vol.I / Issue II /Sept-Nov, 2012/189

[33] Sunday Observer (2013), 'Lack of Financial Literacy, A Drawback for Women in SME Sector', http://www.Sunday observer.lk/2013/09/08/fin30.asp [accessed on 31st October 2013]

[34] The World Bank (2011), World Development Report 2012 Gender Equality and Development, The World Bank, Washington DC.

[35] UNDP (2012), Sri Lanka National Human Development Report 2012; Bridging Regional Disparities for Human Development, UNDP Colombo. 
[36] United Nations University (2013), 'Examining the Entrepreneur Gender Gap', http:// unu.edu/publications/ articles/examining-entrepreneur-gender-gap.html\#info [accessed on 7th May 2013].

[37] Vossenberg S. (2013), “Women Entrepreneurship Promotion in Developing Countries: What explains the gender gap in entrepreneurship and how to close it?”, Working Paper No. 2013/08, The Nation (2013), 'Low Financial Literacy, Crowding Out Women', http:// www.nation.lk/edition/biz-news/item/ 20537-low-financial-literacy-crowding- out-women.html [accessed on 31st October 2013].

[38] Wickramasinghe, M. (2000), From Theory to Action, Women Gender and Development. Friedrich -Ebert-Stiftung, Colombo. Sri Lanka

\section{AUTHORS}

\section{Biographical Sketch}

Dr. Sriyani Ranasinghe is a Head of the department and the Senior Lecturer at the Department of Entrepreneurship, Faculty of Management Studies and Commerce, University of Sri Jayewardenepura, Sri Lanka. She obtained her Bachelors in Management Studies degree with a first class from the Open University of Sri Lanka. She has obtained the Master of Science in Organizational Management postgraduate degree from University of Peradeniya, and followed up with a PhD in Business Management from Management and Science University in Malaysia. Her passion is teaching with the specialized area of the Entrepreneurship. She is doing many CSR on behalf of the community through the International Association of Lions Clubs 306C2 in Sri Lanka as the Zone Chair Person.

As an enthusiastic goal-oriented person, she strongly believe that the key to success is commitment and being an effective team player. Her strategic goal is to be a well-known academic member with excellent applied research to enhance the entrepreneurialism and innovative practices and systems in the world of works. Openmindedness, trustworthiness, mindfulness and honesty are some of her core values. She is extremely appreciate, care, respect for the different views, ideas and values of others.

Correspondence Author - Author name, email address, alternate email address (if any), contact number.

\section{Dr. H. K G S Ranasinghe \\ Email: hksri@sjp.ac.lk \\ hksrient@gmail.com, \\ hksrient2@gmail.com}

\section{Mob: +9477 6500518}

